\title{
Luís Heitor Corrêa de Azevedo: o Cinquientenário de um Livro
}

\author{
RÉGIS DUPRAT
}

A mais completa coletânea sobre a vida e a obra de Luís Heitor Corrêa de Azevedo (1905-1992) está contida na Edição Comemorativa dos 80 anos do musicólogo, publicada em 1985 pela Sociedade Brasileira de Musicologia, sob a coordenação de Dulce Martins Lamas, com apoio da Funarte.

O volume contém excelente síntese biográfica apresentada pela coordenadora da edição, sob o título: "Luís Heitor, uma personalidade na música universal". Inclui, ainda, exaustiva "Relação das Publicações de L. H." (pp. 141-169) que reúne 1. Livros e Folhetos; 2. Participação em Congressos; 3. Colaboração em obras diversas; 4. Coletâneas em Dicionários e Enciclopédias; 5. Colaboração em Revistas de Música; 6. Colaboração em Outros Periódicos; 7. Colaboração na Imprensa Diária; 8. Entrevistas e Questionários; 9. Prefácios; 10. Apresentação em Gravações Fonográficas; 11. Notas em Programas de Concerto; 12. Juvenília; 13. Composições Musicais. Essa relação contém cerca de 450 títulos, que incluem 250 artigos na imprensa diária, ou seja, a atividade jornalística de Luís Heitor.

A publicação apresenta, ainda, evocações autobiográficas de Luís Heitor de suas memórias da Unesco, sobre Villa Lobos e Nádia Boulanger, além de três textos sobre a música em geral e outros três sobre a música brasileira, todos selecionados dentre publicações de Luís Heitor e hoje de difícil acesso. Completam o volume 16 pequenos testemunhos sobre Luís Heitor, de personalidades musicais brasileiras.

Essa edição constitui, ainda hoje, a mais completa informação sobre o grande musicólogo brasileiro que, de 1947 a 1965, atuou proficua- 
mente junto à Unesco no planejamento, organização, implantação e funcionamento das atividades musicais daquele importante órgão internacional das Nações Unidas.

No início do ano de 1944, retornando de uma viagem a Minas Gerais, ainda com mais alguns dias de férias, Luís Heitor deu-se conta de que começava a envelhecer sem ter publicado um livro sequer. Em 13 de dezembro de 1943 ele acabara de completar 38 anos, mas acumulara substancial produção na imprensa diária do Rio de Janeiro, especialmente entre os 23 e os 30 anos de idade (1928-1935). Essa atividade não cessara jamais inteiramente, não obstante a maciça concentração nos anos de 1928-1929, em que atuara na crítica musical de $O$ Imparcial, do Rio de Janeiro, por oito meses (agosto de 1928 a março de 1929), com 22 críticas, e em A Ordem, da mesma cidade (março de 1929 a outubro de 1930), com 177 crônicas em 20 meses. Ainda em 1944-1945, colaboraria com assiduidade em A Manhã, também de sua cidade natal. Nesses três títulos reúne-se quase $90 \%$ de sua produção crítica na imprensa diária, durante toda a sua vida. Valendo-se dessa produção no campo da crítica, Luís Heitor concebeu, naquele verão de 1944, publicar três livros: um, sobre a música (e os músicos) do Brasil; outro, sobre o que chamou de "música nativa" e que, não obstante a farta produção para isso, jamais seria publicado; e um terceiro, sobre a "música de fora e as questões musicais gerais", como ele chamou, e que também não veio à luz. Com prefácio de junho de 1946, o primeiro projeto foi publicado em 1950 (Música e Músicos do Brasil, Rio de Janeiro, Casa do Estudante), quando o autor contava 45 anos, "... idade avançada para publicar um primeiro livro..." como advertia então, mas de que se orgulhava, pois laborara desinteressadamente, sem vaidade e sem sobressaltos, sem pensar em escrever o livro que já havia escrito... Complementou-o com conferências e trabalhos musicológicos importantes, ainda não publicados até aquela data, como por exemplo, a instâncias do próprio Mário de Andrade, a sua comunicação ao Congresso de Língua Nacional Cantada, realizado em São Paulo em 1937, os textos sobre o Hino Nacional Brasileiro e sobre o padre José Maurício Nunes Garcia (1767-1830) e vários outros relevantes temas musicológicos. Dentre estes, provavelmente escrito adrede para a publicação, ressalta "A Música Brasileira e seus Fundamentos”, que integra a Introdução de 
Música e Músicos do Brasil. Trata-se de um texto denso, de 27 páginas, que podemos considerar de antológica importância para a reflexão sobre a música brasileira e que comentaremos aqui, numa comemoração antecipada dos 50 anos da publicação, em 1950, de Música e Músicos do Brasil.

Nesse texto, Luís Heitor busca, inicialmente, caracterizar uma identidade brasileira. Nisto ele ainda se situa dentro do movimento modernista da década de 1920, o que denota que o tema não envelhecera, ou pelo menos não se esgotara. É sabido que o tópico da identidade não nasceu com o modernismo. Há toda uma rica literatura que aborda as raízes novecentistas da discussão que inspirou acalorada colaboração da nossa intelectualidade, dos nossos escritores, poetas e artistas, desde a independência. Esta, teria sido um ato político que requeria aprimoramento teórico e ideológico para que a nação se tornasse também social e culturalmente independente, respaldando reciprocamente a independência política.

O tema da identidade sempre inspirou a nossa produção cultural. Na música, chegamos à década de 1950 com esse problema ainda não resolvido; ou ainda digno de reparos e reflexões; um caldeirão pedindo lenha na fervura do após-guerra. Para Luís Heitor, a identidade brasileira já se define preliminarmente pela língua portuguesa e pelo regime monárquico que a diferencia, nos primórdios da instauração da nação, das limítrofes repúblicas hispano-americanas. Outro fator para ele ponderável é o de que a música seria a mais sociológica e popular das artes, e que emana mais diretamente do povo. Cabe observar aqui a estreita vinculação dessas ponderações com a postura de Mário elegendo a música popular brasileira como a mais pura vocação para caracterizar a "identidade nacional". (Ensaio sobre a Música Brasileira, 3ª edição, Martins/INC-MEC, 1972, p. 24). Em Aspectos da Música Brasileira (Belo Horizonte, Vila Rica, 1991, p. 14) Mário já ressaltava a característica da música como "a mais coletiva de todas as artes, exigindo a coletividade dos ouvintes [...] e imediatamente sujeita às condições da coletividade".

Invocando autores que não importa citar aqui, Luís Heitor nota que, no Brasil, o europeu não se sobreporia como classe dominante e antagônica, mas conviveria num nivelamento fecundo que seria singular em todo o hemisfério sul. O predomínio do branco só teria ocorrido no Brasil 
de 1850 em diante, em consequiência do surto migratório e econômico no sul do país, inclusive, depois, dali em direção ao norte-nordeste. Invocando as "verdades fundamentais" de nossa música, Luís Heitor observa que a nossa música tradicional continuava sendo a "flor amorosa de três raças tristes", síntese consubstanciada na imagem poética de Olavo Bilac, em seu célebre soneto sobre a Música Brasileira inserido em Tarde, seu livro póstumo, editado em 1919.

Reiterando Mário (Ensaio..., pp. 14-16), Luís Heitor também se descarta de sugestões de comentaristas europeus que viam na música dos indígenas o caminho da originalidade para a nossa música erudita. Como a Mário, não o impressionava sequer o sucesso europeu de Villa Lobos, que na década de 1920 teria, com "melodias indígenas" e até com palavras tupi, configurado exoticamente a sua produção da fase parisiense. Luís Heitor se convencia da identidade brasileira diversificada da dos países hispano-americanos, nos quais a canção popular sofrera forte impacto das músicas indígenas, ou seja, de povos autóctones cujas características culturais andinas eram acentuadamente diversas das dos nossos indígenas. Mas não é apenas essa diferença cultural dos nossos autóctones, contrapondo América Espanhola e América Portuguesa, que equaciona todo o problema. Parece ser, muito mais, a influência relativa daquela música na formação do que Luís Heitor, acompanhando o pensamento musicológico daquelas décadas, denominava "canção popular" no Brasil. Assim, ele incorpora à sua argumentação os depoimentos de Mário e Gallet; este último, não querendo identificar com clareza a contribuição direta do indígena; e Mário, alegando assimilação psicológica dos elementos ameríndios no populário brasileiro, assimilação essa que, deglutida, teria tornado a presença dos elementos indígenas, como dizia Mário, quase nula. Para Luís Heitor, a presença temática indígena soaria tão exótica para os brasileiros como para os europeus. $\mathrm{E}$ as singularidades etnoculturais dos hispano-americanos não teriam correspondência no Brasil, onde os fundamentos da música nacional não estariam no conjunto das pesquisas etnomusicais, por sinal louváveis, realizadas até então, inclusive, como sabemos, por ele próprio.

O que nem Mário nem Luís Heitor comentam é a origem mais remota das referidas "sugestões" de comentaristas europeus para que a música artística brasileira se construísse sob a inspiração original da cultura indígena. Nem citam a obra fundadora dessa postura que seria o 
Résumé de l'Histoire Littéraire du Portugal, suivi du Résumé de l'Histoire Littéraire du Brésil, Paris, Lecointe et Durey, 1826, de Ferdinand Denis (1798-1890) (ver Guilhermino César, Historiadores e Críticos do Romantismo, Rio de Janeiro, Livros Técnicos e Científicos; São Paulo, Editora da Universidade de São Paulo, 1978, pp. 27-82).

Luís Heitor detectava a musicalidade do índio no canto caboclo do norte do Brasil, em contraposição ao Brasil negro e mulato, da Bahia e outros centros. Para ele, a diferenciação era melódica, rítmica e organológica, elementos mais perceptíveis do que ele chamava de "sutil processo de tipificação nacional". Num detalhamento poucas vezes relembrado ou rediscutido, ele contrapõe as "feições" negra e cabocla do nosso populário musical. A cabocla se afastaria mais do canto europeu. Nela, "tonalidade e simetria rítmica se diluem numa faixa melódica extremamente livre, em que a altura dos sons", organizados em escalas e "sua divisão métrica" nada teriam em comum com o sistema ocidental moderno.

A feição negra seria para Luís Heitor "melodicamente mais dócil à supremacia européia", com simetria rítmica no deslocamento da sincopação. A predominância acentuada da percussão reafirmaria também a presença organológica negra em nossa música popular ou, como diz, em nossa folkmúsica.

Retornemos às primeiras páginas do Ensaio... de Mário, para confrontá-las à luz do texto de Luís Heitor, em questão. Se contextuarmos no conjunto das primeiras páginas do Ensaio... a citação lacônica que Luís Heitor faz de Mário, ou seja, de que "[o] elemento ameríndio no populário brasileiro está psicologicamente assimilado e praticamente já é quase nulo", verificaremos que a frase se integra justamente na refutação do que Mário chama de conselhos europeus para se fazer música (artística) de forma legitimamente brasileira. Segundo Mário, tais conselhos seriam fruto do gosto pelo exótico. O exotismo é um elemento que tem fascinado uma certa literatura musicológica internacional, voltada especialmente para as análises e abordagens da música do período romântico internacional. Entretanto, o exotismo não constituía novidade para Mário em 1928, e em 1946, 18 anos depois, data em que provavelmente Luís Heitor redige o capítulo sobre os Fundamentos da Música Brasileira para introduzir Música e Músicos..., publicado em 1950, e no qual Luís Heitor exuma o conceito de exotismo como instrumento ou 
critério de reflexão para uma compreensão e interpretação de uma identidade nacional brasileira. Estamos ainda no ciclo histórico do modernismo.

Há uma sintonia Mário - Luís Heitor, mas o elemento novo neste último parece ser a feição cabocla em contraposição à feição negra, já comentada. De início, parece claro que ambos estão se referindo, nos textos que tratamos aqui, à música artística brasileira, ou seja, aquela produção dos compositores eruditos que utilizariam ou não tais ou quais elementos para compor música artística.

O tópico abordado por Luís Heitor nesse texto, sobre a debatida origem da síncopa melódica na música brasileira, parece constituir, também, um tema esquecido em nossa musicologia. Em seu texto aqui destacado, Luís Heitor já encara a síncopa melódica como um enigma que tem desafiado nossos pesquisadores, cujas propostas alternativas não haviam, até então, persuadido os observadores superficiais a abandonar a tese da procedência africana da síncopa. Passado quase meio século da publicação de Música e Músicos... esse quadro não parece ter se modificado.

Citando o trabalho de Mário, Introdução aos Estudos do Folclore de Luciano Gallet, Luís Heitor adere à tese deste último de que “... a nossa síncopa [...é] vinda não do africano mas do 6/8, allegro deformado por influência do ritmo africano existente então". Com exemplos rítmicos musicais, Luís Heitor reitera a tese de Gallet de que a síncopa “... pode ter surgido de uma adulteração do $6 / 8$ tão constante da rítmica ibérica, acompanhado pelas batidas de divisão e subdivisão binária dos tambores africanos: o ritmo composto ter-se-ia convertido, por injunção de acompanhamento 2/4, na fórmula básica sincopada; e arremata: "Que o folclore musical negro do Brasil tenha adotado um formulário melódico em que são evidentes os acentos europeus da canção portuguesa, é constatação que sem dificuldade se pode fazer".

No Ensaio... (1928, pp. 30-39), Mário dedica várias páginas ao comentário sobre a síncopa, que para ele é uma constância da música brasileira "mas não uma obrigatoriedade", pois "muitas vezes a gente chama de síncopa o que não o é”, e que "... esses processos de rítmica oratória, desprovida de valores de tempo musical contrastavam com a música portuguesa afeiçoada ao mensuralismo tradicional europeu. Deuse pois na música brasileira um conflito entre a rítmica diretamente 
musical dos portugueses e a prosódica das músicas ameríndias, também constante nos africanos aqui. E a gente pode mesmo afirmar que uma rítmica mais livre, sem medição isolada musical era mais da nossa tendência..." E mais adiante: "É possível que a síncopa, mais provavelmente importada de Portugal que da África (como de certo hei de mostrar num livro futuro) tenha ajudado a formação da fantasia rítmica do brasileiro". E, já ao fim do capítulo sobre a síncopa, Mário recorda que certos binários compostos, de influência portuguesa, permaneceram na música nordestina do Brasil.

Se a primeira parte do capítulo A Música Brasileira e seus Fundamentos está dedicada aos aspectos conceituais aqui abordados, especialmente no que tange à importância da etnomúsica, a segunda parte desenvolve-se à guisa de uma síntese da trajetória histórica da música culta no Brasil. Refletindo o estado das pesquisas até então desenvolvidas sobre o Brasil colonial, o texto é extremamente frugal. A polêmica existência da Fazenda de Santa Cruz, nas cercanias do Rio de Janeiro, onde os jesuítas teriam mantido um Conservatório de Negros, é vista por Luís Heitor com certa incredulidade, não obstante reconhecer que no período colonial as grandes fazendas manteriam bandas de escravos e a de Santa Cruz pudesse constituir uma delas, mais exemplar e organizada. Era certo para o autor, entretanto, que não obstante os jesuítas se terem erigido como os primeiros mestres, inclusive na música, não deixaram lembrança de nenhum músico que pudesse ombrear-se com a figura notória e consagrada de um Antônio Vieira. Pelo contrário, são os Franciscanos, Carmelitas e os padres seculares os que contribuirão para notabilizar os nomes dos primeiros músicos importantes no Brasil.

Para o Luís Heitor de Música e Músicos..., a música do período colonial se resume ao padre José Maurício, da corte do príncipe D. João. Apenas Marcos Portugal é citado por seu vínculo com a inauguração, em 1813, das temporadas de grandes óperas na corte. De passagem, é citado também Sigismund Neukomm, discípulo e admirador de José Maurício.

É de destacar a ausência de qualquer referência às pesquisas, então recentes, comunicadas por Francisco Curt Lange no Boletim Latino-Americano de Música, publicado em Montevideu, em 1946, revelando a por ele chamada Escola Mineira de Compositores do período colonial. A observação que fizemos acima, de que Luís Heitor teria 
elaborado o capítulo introdutório juntamente com o Prefácio, que data de 1946, seria o motivo da ausência daquela comunicação tão importante para a musicologia brasileira do período colonial. Entretanto, dois tópicos nos desconfortam nessa interpretação, ambos atinentes à repercussão de época, nas décadas de 1949-1950, das descobertas de Lange. O período de quatro anos, que separaria a elaboração da introdução da publicação de Música e Músicos..., seria suficiente para uma inclusão emergencial de um capítulo, parágrafo ou nota de rodapé, caso as descobertas tivessem realmente causado impacto nos meios musicológicos, mesmo considerando a conhecida celeuma criada, especialmente na crítica musical carioca, sobre a autenticidade das obras divulgadas por Lange. Entretanto, o terceiro livro de Luís Heitor, 150 Anos de Música no Brasil, publicado em 1956, também não contém nenhuma referência às descobertas de Minas Gerais, apesar de sob o título de "Antecedentes", que abre aquela obra, o autor ampliar as informações sobre o período colonial numa magnífica síntese das atividades musicais nos primórdios, na catequese, na crônica, nas igrejas, nos teatros e nas festas.

É certo que, a partir das pesquisas de Lange, iniciadas na década de 1940, mais precisamente em 1944, sobre a música nas Minas Gerais, a historiografia sobre o período colonial não fez senão crescer ininterruptamente, ganhando ricos acrescentamentos nas décadas de 1960-1970 com as minhas descobertas do Recitativo e Ária datado da Bahia, 1759, e das obras de André da Silva Gomes (1752-1844) e as atividades musicais na Sé de São Paulo; e as riquíssimas pesquisas de Jaime Diniz sobre Pernambuco e a obra de Luís Álvares Pinto (17191789). A própria música mineira recebeu, em desdobramentos posteriores, contribuições enriquecedoras, sendo objeto de pesquisas reveladoras, como as de G. Olivier Toni e Conceição Resende. E em matéria de organização de arquivos e catalogação temática, as contribuições de Cleofe Person de Mattos sobre a obra de José Maurício, o Catálogo sobre o Ciclo do Ouro em Minas Gerais, os do Museu da Inconfidência de Ouro Preto, de Régis Duprat e Carlos Alberto Baltazar; a minha catalogação da obra de André da Silva Gomes, além de fartos estudos monográficos de uma nova geração altamente produtiva e de registros fonográficos, como os dos Festivais de Juiz de Fora. Mas essa realidade reflete apenas um desenvolvimento posterior da 
pesquisa, que Luís Heitor só conheceu e incorporou à sua produção musicológica em data mais recente.

Já a abordagem da música no período imperial, que se concentra na figura de Francisco Manuel da Silva, muito pouco evoluiu com relação ao texto de Música e Músicos... É igualmente rica a vertente da música de teatro e a ópera de Carlos Gomes e os movimentos liderados por José Amat, com relação à ópera nacional. Da mesma forma o advento da música de concerto no século dezenove e as contribuições das sociedades de concerto e clubes, assim como a obra e atuação social de Miguez, Oswald, Nepomuceno e Levy para a consolidação dos instrumentos educacionais e formação dos músicos instauradas com tanto empenho e lucidez por Francisco Manuel da Silva.

É evidente que uma síntese de 30 páginas exige do autor uma concentração sobre os grandes nomes da composição musical em cada período abordado, se bem que no capítulo III, "Compositores e suas Obras", inserido no livro, o autor arrole estudos, ainda que sintéticos, sobre 20 compositores, de José Maurício a H. J. Koellreuter. Sobre este último, aliás, salvo os elogios ao empenho do então jovem compositor, Luís Heitor não deixa transpirar nenhuma vertente do que foi, no mesmo ano da publicacão de Música e Músicos..., ou seja, 1950, a divulgação da Carta Aberta, de Camargo Guarnieri, sobre o movimento dodecafonista brasileiro liderado por Koellreuter e o Grupo de Música Viva, com seu manifesto de 1946, e a apaixonada polêmica gerada por esses documentos na época.

Notemos que o ano de 1950 representa, pois, um marco na evolução da nossa música e, em certo sentido, um divisor de águas com relação à postura diante do problema ainda modernista da identidade nacional, da modernização estética e da atualização de técnicas e processos de composição, interpretação e recepção de repertório musical. Considerações sobre essa vertente, já em elaboração, reservamo-las para outra oportunidade. Ressaltemos, porém, que o marco representado pela data de 1950 incorpora Música e Músicos... ao período que aí se encerra e do qual podemos considerá-lo obra emblemática. 